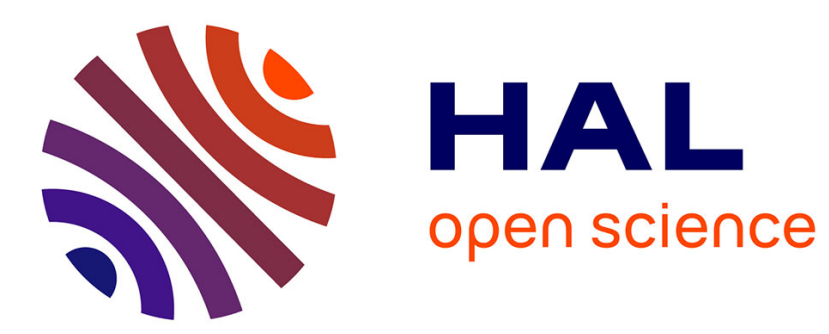

\title{
Maternal depression trajectories and children's behavior at age five years
}

Judith van Der Waerden, Cédric Galéra, Béatrice Larroque, Marie-Josèphe Saurel-Cubizolles, Anne-Laure Sutter-Dallay, Maria Melchior

\section{- To cite this version:}

Judith van Der Waerden, Cédric Galéra, Béatrice Larroque, Marie-Josèphe Saurel-Cubizolles, AnneLaure Sutter-Dallay, et al.. Maternal depression trajectories and children's behavior at age five years . The Journal of Pediatrics, 2015, pp.22. 10.1016/j.jpeds.2015.03.002 . hal-01148714

\section{HAL Id: hal-01148714 https://hal.sorbonne-universite.fr/hal-01148714}

Submitted on 5 May 2015

HAL is a multi-disciplinary open access archive for the deposit and dissemination of scientific research documents, whether they are published or not. The documents may come from teaching and research institutions in France or abroad, or from public or private research centers.
L'archive ouverte pluridisciplinaire HAL, est destinée au dépôt et à la diffusion de documents scientifiques de niveau recherche, publiés ou non, émanant des établissements d'enseignement et de recherche français ou étrangers, des laboratoires publics ou privés. 
Judith van der Waerden, $\mathrm{PhD}^{12}$; Cédric Galéra, $\mathrm{MD}, \mathrm{PhD}^{345}$; Béatrice Larroque MD, $\mathrm{PhD}^{26}$; MarieJosèphe Saurel-Cubizolles, $\mathrm{PhD}^{26}$; Anne-Laure Sutter-Dallay, $\mathrm{MD}, \mathrm{PhD}^{478}$; Maria Melchior, $\mathrm{ScD}^{12}$ and The EDEN Mother-Child Cohort Study Group

\section{Affiliations:}

${ }^{1}$ INSERM UMR_S 1136, Pierre Louis Institute of Epidemiology and Public Health, Department of Social Epidemiology, F-75013 Paris, France

${ }^{2}$ Sorbonne Universités, UPMC Univ Paris 06, F-75005 Paris, France

${ }^{3}$ Department of Child and Adolescent Psychiatry, Charles Perrens Hospital, F-33000 Bordeaux, France

${ }^{4}$ Bordeaux University, F-33000 Bordeaux, France

${ }^{5}$ INSERM U897, Center for Research in Epidemiology and Biostatistics, Prévention et Prise en Charge des Traumatismes, F-33000 Bordeaux, France

${ }^{6}$ INSERM, UMR_S 953, Epidemiological Research on Perinatal Health and Women's and Children's Health, F-94807 Villejuif, France

${ }^{7}$ INSERM U657, F-33000 Bordeaux

${ }^{8}$ University Department of Adult Psychiatry, Charles Perrens Hospital, F-33000 Bordeaux, France

\section{Address correspondence to:}

Judith van der Waerden

Pierre Louis Institute of Epidemiology and Public Health, INSERM \& Sorbonne Universités UPMC Hôpital Paul-Brousse, Bâtiment 15

16 avenue Paul Vaillant Couturier, 94807 VILLEJUIF CEDEX, France

judith.van-der-waerden@inserm.fr,

Tel: +33(0)1 777474 31/ Fax: +33 (0)1 45595080

No reprints

Key Words: internalizing and externalizing problems; Maternal depressive symptoms; Trajectory analysis 
Funding source: Fondation pour la Recherche Médicale (FRM), French Ministry of Research: IFR Program, INSERM Human Nutrition National Research Program, and Diabetes National Research Program (through a collaboration with the French Association of Diabetic Patients (AFD)), French Ministry of Health, French Agency for Environment Security (AFSSET), French National Institute for Population Health Surveillance (InVS), Paris-Sud University, French National Institute for Health Education (INPES), Nestlé, Mutuelle Générale de I'Education Nationale (MGEN), French speaking association for the study of diabetes and metabolism (ALFEDIAM), National Agency for Research (ANR nonthematic programme), National Institute for Research in Public Health (IRESP: TGIR Cohorte Santé 2008 programme). This study was funded by the French National Research Agency (ANR, Program on Social Determinants of Health).

Dr. van der Waerden wrote the first draft of the manuscript and it has been read and approved by all authors. None of the authors have a potential conflict of interest to report, nor received any form of payment to produce the manuscript 


\section{Abstract}

\section{Objective}

To assess the relationship between trajectories of maternal depression from pregnancy to the child's age 5 and children's emotional and behavioral difficulties at age 5 .

\section{Study design}

1183 mother-child pairs from the EDEN mother-child birth cohort study based in France were followed from 24-28 weeks of pregnancy to the child's fifth birthday. Children's behavior at age 5 was assessed using the Strengths and Difficulties Questionnaire. Maternal depression was repeatedly assessed with the Center for Epidemiological Studies Depression questionnaire (pregnancy, 3 and 5 years) and the Edinbourgh Postnatal Depression Scale (4, 8, and 12 months postpartum). Homogeneous latent trajectory groups of maternal depression were identified within the study population and correlated with SDQ scores using multivariate linear regression analyzes.

\section{Results}

Five trajectories of maternal symptoms of depression were identified: no symptoms (62.0\%); persistent intermediate-level depressive symptoms (25.3\%); persistent high depressive symptoms (4.6\%); high symptoms in pregnancy only (3.6\%); high symptoms in the child's preschool period only (4.6\%). Children whose mothers had persistent depressive symptoms - either intermediate or high had the highest levels of emotional and behavioral difficulties at age 5. Additionally, compared to children whose mothers were never depressed, those whose mothers had high symptoms in the preschool period also had elevated levels of emotional symptoms, conduct problems, and peer problems.

\section{Conclusions}

Maternal depression symptoms are related to children's emotional and behavioral problems, particularly if they are persistent (29.9\%) or occur during early childhood (4.6\%). 


\section{Introduction}

Maternal depression has been consistently found to be detrimental to children's emotional and behavioral development throughout life. ${ }^{1,2}$ Depressive episodes during pregnancy may affect fetal development, modifying the child's temperament, and increasing rates of attentional, emotional and behavioral problems later on. ${ }^{3-6}$ The first year of life is a 'sensitive' period in terms of emotional regulation and attachment, and maternal depression in infancy can also hinder psychosocial development. ${ }^{7-9}$ Similarly, during later periods of development maternal depression can have negative effects on the child's socialization and ability to establish satisfactory relationships with others, which increase the likelihood of both externalizing and internalizing problems. ${ }^{10-13}$ Moreover, chronic maternal depression predicts children's behavior both in the short and longterm. ${ }^{14-16}$ It may therefore be that, rather than timing, the key feature of maternal depression with regard to children's behavior is symptoms' persistence over time. ${ }^{14}$

However, research on the timing, chronicity and severity of depressive symptoms in women with young children has often relied on cross-sectional data, which fails to fully capture the longitudinal trajectory of maternal symptoms of depression. Recently developed statistical methods make it possible to model data from studies of sufficient duration, separating out the course and severity of symptoms over time. ${ }^{17,18}$ To date, only a limited number of studies have used such methodology to examine the role of maternal depression from infancy to late childhood in relation to children's behavior, ${ }^{19-23}$ reporting that the chronicity of maternal depression is probably the key element with regard to children's development. Yet failure to account for maternal depression in pregnancy prevents from firmly concluding that the timing of maternal depression is less relevant. To our knowledge, only Cents et $\mathrm{al}^{22}$ followed mothers and children from mid-pregnancy onwards, and found that the chronicity and severity rather than timing of maternal depression was associated with children's behavior at age 36 months. However, its association with children's behavior at older ages is not known.

The objective of this study was to examine the relationship between trajectories of maternal symptoms of depression -distinguishing a chronic course from depressive symptoms in particular developmental periods - from pregnancy to the child's fifth birthday and children's behavior using data from the EDEN study, a longitudinal community based cohort study conducted in France. Our analyses controlled for maternal, family and child characteristics that can be associated with both maternal depression and children's outcomes. ${ }^{24}$ 


\section{Methods}

\section{Participants}

Participants of the EDEN mother-child birth cohort study ${ }^{25}$ were recruited between 2003-2006 among pregnant women (24 weeks of amenorrhea) followed in two maternity wards in Poitiers and Nancy University hospitals (France). Exclusion criteria were multiple pregnancies, a known history of diabetes, the inability to speak and read French or plans to move out of the study region in the following 3 years. Among eligible women, 55.0\% ( $n=2002)$ agreed to participate and birth data were obtained from 1899 mother-infant pairs. During pregnancy and after birth (4, 8, 12, 24 months, 3, 4 and 5 years), socio-demographic and biomedical data on mother and child were gathered from medical records, face to face interviews with the mother and mother's self-completed questionnaires. By the year 5 follow-up, data were available for 1183 (62.5\%) participating mothers and children. Attrition was highest in young mothers $(p<.001)$, those with low educational level $(p$ $<.001)$, of non-French origin $(p<.001)$, who did not live with the father of their child $(p=.002)$, as well as those who were depressed during pregnancy $(p<.001)$ or in the postpartum period $(p=.002)$. Written consent was obtained from the mother for herself at inclusion and for her newborn child after delivery. The study was approved by the Ethics Committee of Kremlin Bicêtre hospital and by the French Data Protection Authority.

\section{Measures and procedures}

\section{Maternal depressive symptoms}

Maternal symptoms of depression in pregnancy and at 3 and 5 years follow-ups were assessed using the Center for Epidemiological Studies Depression (CES-D) questionnaire, ${ }^{26}$ a 20 -item questionnaire measuring the number of symptoms over the preceding week (range 0-60) with high reliability and validity. ${ }^{27}$ While not specifically designed to measure depression in pregnancy, the CES-D has been previously used in pregnant women. ${ }^{28,29}$ The average Cronbach's alpha across the three measurement moments was 0.88 . Maternal symptoms of depression during the first year after the child's birth (4, 8 and 12 months postpartum) were assessed using the Edinburgh Postnatal Depression Scale (EPDS), a 10-item questionnaire designed to detect postnatal depression (range 030). ${ }^{30}$ Across the three measurement points, Cronbachs alpha was 0.85 .

To identify trajectories of maternal depressive symptoms we needed to meaningfully combine the scores of both instruments, which have different possible symptom severity score ranges. Thus, the scores for each instrument were standardized to t-scores ( $M=50, S D=10)$, which allowed us to study them jointly as continuous measures. ${ }^{31}$ 


\section{Child behavior}

Children's behavior at age five was ascertained by the mothers using the Strengths and Difficulties Questionnaire (SDQ), ${ }^{32}$ a questionnaire designed to assess the behavior and emotions of 3- to 16 year-olds. The SDQ consists of 25 items which are divided into 5 subscales (range 0-10): emotional symptoms, conduct problems, symptoms of hyperactivity/inattention, peer relationship problems and pro-social behavior. All subscales (except pro-social behavior) are summed to obtain a score of children's overall behavioral problems (range 0 to 40). The SDQ has good psychometric characteristics and is comparable to other measures such as the $\mathrm{CBCL}^{33}$ In our sample, Cronbach's alpha for overall behavioral problems was 0.79 .

\section{Covariates}

Covariates included in the multivariate analysis include maternal, family and child characteristics ascertained at study baseline unless indicated otherwise. Maternal characteristics were: maternal age at the child's birth, years of formal education, maternal anxiety in pregnancy (STAI ${ }^{34}$ score), history of mental health problems (no vs. yes), maternal antidepressant use from pregnancy to the $5^{\text {th }}$ year assessment (no vs. yes), maternal prenatal substance use (alcohol, smoking, illicit drugs; no vs. yes), and any breastfeeding (duration in months). Family characteristics were: study center (Poitiers vs. Nancy), family situation from pregnancy to the $5^{\text {th }}$ year assessment (parents living together vs. separated), any low family income from pregnancy to the $5^{\text {th }}$ year assessment $(<1500$ euros/month, category closest to the bottom quartile; no vs. yes), number of siblings living at home, child care arrangements from birth to the child's $3^{\text {rd }}$ year (mother vs. others), any domestic violence from pregnancy to the $5^{\text {th }}$ year assessment (no vs. yes), social support (no vs. yes) and paternal substance abuse (no vs. yes). Child characteristics included: child's sex (male vs. female), premature birth ( $\leq 37$ vs. $>37$ weeks of gestation), and small for gestational age (no vs. yes).

\section{Statistical analyses}

Our aim was to assess the association between trajectories of maternal symptoms of depression and children's behavior. First we calculated trajectories of maternal symptoms of depression using growth trajectory models (PROC TRAJ in SAS 9.3), a group-based semi-parametric method which makes it possible to identify distinct clusters of individual trajectories within the population. ${ }^{17,35}$ Missing data are handled by PROC TRAJ under the missing-at-random assumption, which allows patterns with missing values to share information with patterns with more data points through the latent variable. Individuals with missing data were assigned to their most likely group. ${ }^{36}$ To determine the optimal model of depression trajectories, we used statistical indices as well as the overall interpretability. As previous research had led us to expect to find 3 to 6 trajectory groups, 
models with 3-6 trajectories were estimated using a censored normal distribution. We used the Bayesian information Criteria (BIC) to identify the best-fitting model with the least number of trajectories. The BIC scores continued to improve from the three-group to the six-group model, and ranged from -24493.62 to -24326.91 . Although the BIC score was somewhat better for the six-group model than for the five-group model (-24369.08), we adopted the latter since the six-group solution subdivided the sample into smaller groups (one additional group of $2.2 \%$ ) that did not improve the classification of subjects. Next, the model was refined by selecting the shape (i.e. linear, quadratic, cubic) of each group's trajectory over time. ${ }^{36}$ To define a good model, the average posterior probabilities of trajectory membership should be at least equal to 0.7 for all groups. ${ }^{17}$ The average posterior probabilities of group membership were above 0.80 for all trajectories in the five-group model (range 0.81- 0.95, M=0.87) and slightly superior to those for the six-group model (range $0.79-$ $0.95, M=0.85)$.

Second, we tested univariate associations between potential covariates and trajectories of maternal depression as well as children's behavior scores using linear regression models. Third, associations between trajectories of maternal depression and children's behavior were studied controlling for all covariates significantly associated $(p<.10)$ with children's overall behavior score. We found no statistically significant interactions between maternal depression and the child's sex, mother's educational level and family income; therefore all children were studied simultaneously. To account for the possible effect of concurrent maternal depression at age 5 on ratings of children's behavior, we rerun the trajectory analysis with omission of this latest data point, and repeated the analyses based on these trajectories.

In secondary analyses, CES-D and EPDS scores were dichotomized at their respective cut-off points (CES-D score $\geq 16$ and an EPDS score $\geq 12$ ) $^{26,37}$ in three discrete time periods, i.e. pregnancy, the first postpartum year (4, 8 and 12 months), and the child's preschool period (3-5 years). Multiple linear regression models were used to examine associations between maternal depression at each of the three time points and children's behavioral problems. To account for the effect of concurrent depression at age 5, analyses were repeated with exclusion of this latest time point. Trajectories of maternal depression were studied using PROC TRAJ in SAS V9.3. All other analyses were performed using SPSS version 19.

\section{Results}

Table 1 presents maternal, family and child characteristics of the 1183 study participants with complete data up to the 5 year assessment. 


\section{Trajectories of maternal symptoms of depression}

The five trajectories of maternal symptoms of depression (Figure 1) from pregnancy up until the child's $5^{\text {th }}$ year were: no symptoms $(62.0 \%, n=736)$; persistent intermediate-level depressive symptoms (25.3\%, $n=297)$; persistent high depressive symptoms ( $4.6 \%, n=54)$; high symptoms in pregnancy only $(3.6 \%, n=42)$; high symptoms in the child's preschool period only $(4.6 \%, n=54)$.

\section{Maternal depression trajectories and child behavior}

Table 2 displays results of linear regression models showing relationships between the trajectories of maternal symptoms of depression and children's behavior at age 5. In fully adjusted regression models, compared to children whose mothers were never depressed, those whose mothers were in the 'persistent high' or 'persistent intermediate' symptoms of depression groups had elevated levels of emotional and behavioral difficulties (emotional symptoms, conduct problems, peer problems, symptoms of hyperactivity/ inattention, low levels of prosocial behavior). Children of mothers with 'high depressive symptoms in pregnancy only,' did not display elevated levels of emotional or behavioral problems. Finally, children of mothers with 'high symptoms in the preschool period only' had elevated levels of emotional symptoms, peer problems and a higher level of overall problems. Overall, the effect of maternal depressive symptoms was comparable across the different subscales of children's emotional and behavioral difficulties. Results were slightly attenuated but remained consistent when concurrent maternal depression at age 5 was excluded from the analyses. In secondary analyses, maternal high depressive symptoms in pregnancy, postpartum, and the child's preschool period were studied in relation to children's behavior. Prenatal depression was not associated with any child behavior, while postpartum and preschool depression were significantly related to the child's emotional symptoms, conduct problems, peer problems, hyperactivity/inattention, and overall SDQ score (Table 3).

\section{Discussion}

Using data from a community based birth cohort study, we identified five distinct trajectory groups of maternal depressive symptoms from pregnancy to the child's $5^{\text {th }}$ year. Children whose mother had persistent symptoms of depression - either intermediate or high-level - were more likely to have high levels of emotional and behavioral difficulties than children whose mother was never depressed from pregnancy onwards. Additionally, children whose mother experienced depressive symptoms when they were in preschool also appeared to have a high likelihood of emotional and behavioral difficulties. In contrast, maternal depression in pregnancy only did not predict children's psychological outcomes later on. Maternal depression early in life, particularly if it persists over time, appears to be associated with children's internalizing and externalizing problems. Our findings 
extend existing literature by showing that symptoms of maternal depression from pregnancy onwards are a key risk factor of children's psychological difficulties, particularly if they are of a chronic nature but also when they occur when children are of preschool age.

\section{Strengths and limitations}

Our study has several strengths: a) a large community sample, b) longitudinal assessments of maternal depression and several covariates, $c$ ) the use of validated measures of mother and child mental health, and d) the availability of multiple measures of maternal, family and child characteristics potentially associated with children's emotional and behavioral development. Our study's main limitations are: first women who were depressed during pregnancy were more likely to have dropped out by the 5 year follow-up. While depression rates in pregnancy were comparable to other studies, ${ }^{6}$ this selective attrition may limited our ability to observe statistically significant associations between maternal depression in pregnancy and children's later behavior problems. However, our use of a group-based modelling strategy allowed us to include subjects with partial data, thus minimizing the impact of attrition bias. Second, maternal depressive symptoms and children's behavior were rated by the mother and could therefore suffer from common method variance. Depressed parents may be especially likely to report high levels of emotional and behavioral problems in their children. ${ }^{38}$ Nonetheless, this does not necessarily imply that the association between parent and child mental health problems is spurious, as depressed parents' ratings have been found to be as accurate as those of other informants ${ }^{39}$ regardless of whether parental depression was ascertained by self-report or clinical diagnosis. ${ }^{2}$ Still, information from multiple informants or behavioral observations may yield more valid and precise measures of children's behavior than maternal reports only, ${ }^{40}$ and should be favored in future research designs. Third, maternal depressive symptoms and children's behavior were ascertained using women's selfreports, rather than clinical diagnoses. While we could not examine the most severe forms of psychopathology, this enabled us to study the entire spectrum of maternal depression and children's behavior, which is a closer estimate of variations in symptomatology at the population level. ${ }^{41}$ Still, associations between clinically assessed maternal depression and children's psychopathology are probably stronger than we report. Fourth, although we took into account a large number of covariates, maternal anxiety was only measured during pregnancy. As anxiety is common and often co-morbid with depression during pregnancy and the postpartum period ${ }^{42,43}$, it may be difficult to clearly attribute symptoms to one or the other condition ${ }^{44}$. Thus we cannot exclude that the EPDS and CES-D scores assessed after birth also capture some components of anxiety. Further, were not able to examine the role of paternal psychopathology which was not measured in the EDEN study. However, we accounted for paternal alcohol abuse, which is often associated with of mental health 
difficulties, thereby probably partly capturing the variability associated with paternal psychopathology. ${ }^{45}$ Although it is unlikely that paternal depression, which can co-occur with maternal depression ${ }^{46}$ can explain our findings, ${ }^{47}$ it should be measured in future studies studying children's behavior.

$\underline{\text { Trajectories of maternal symptoms of depression and children's behavior }}$

Maternal symptoms of depression from pregnancy onwards in our study were best described by five trajectory groups: no symptoms, persistent intermediate-level symptoms level, persistent high-level symptoms, high symptoms in pregnancy only, and high symptoms in the child's preschool period only, which is consistent with earlier studies. ${ }^{19,22}$ Their impact on children's behavior differed relative to trajectory course and occurrence during important developmental periods. Women who were not depressed represent the largest proportion of the sample, indicating that most children do not have mothers that are affected by depression. Children whose mothers had persistent symptoms of depression were more likely to have emotional and behavioral problems than their peers with nondepressed mothers - especially when maternal symptoms appeared to be severe. This pattern appeared across all measured domains of child behavior (emotional symptoms, conduct problems, symptoms of hyperactivity/inattention, peer relationship problems and pro-social behavior), suggesting that the effects of chronic maternal depression, even of subclinical severity, may have deleterious effects on different aspects of child wellbeing. This finding is consistent with the rare studies that established that maternal chronic symptoms of depression of varying severity predict worse offspring adjustment both in the short and long-term. ${ }^{16,20,48}$ Our study has extended these outcomes by showing that chronic patterns of maternal depression may already start during pregnancy and impact child well-being up to 5 years later.

Several mechanisms may explain why maternal depression impacts children's emotional and behavioral development. First, mothers who are depressed transmit to their children a genetic vulnerability to mental health difficulties. ${ }^{49,}{ }^{50}$ This genetic component may be especially strong in case of chronic maternal depression. Second, maternal depression often co-occurs with family risk factors such as marital conflict, socioeconomic disadvantage or paternal psychopathology thereby contributing to an accumulation of negative experiences and exposures. ${ }^{1451}$ Paternal depression is significantly more prevalent when the mother is depressed ${ }^{46}$ which may impact the father' buffering role in the relationship between maternal and child depressive symptoms. ${ }^{52}$ In our study, maternal depression remained significantly associated with children's behavior even after adjusting for several of these environmental risk factors, indicating that it is an important factor predicting children's wellbeing over and above these associated risks. Third, maternal depression may interfere with the quality of the parent-child relationship, which in early years of development is an important 
regulator of children's emotions and behavior. ${ }^{11}$ In particular, mothers who are depressed have less frequent and less positive interactions with their children and lower parenting self-efficacy than mothers who are not depressed. ${ }^{53}$ Intervention studies in which maternal depression is treated show improvements in children's behavior, supporting the hypothesis that the environmental influence of maternal depression on children's well-being is key. ${ }^{54}$

\section{Timing of maternal symptoms of depression and children's behavior}

Examining the timing of maternal depression trajectories, we found that only maternal depression when the child was of preschool age was associated with children's internalizing, externalizing and peer problems, though to a smaller extent than persistent depression. This pattern was observed even after we limited the measurement of maternal depression in the preschool year to the measure obtained when the child was 3 years of age. Our secondary analyses showed that the impact of maternal depression was greater during the preschool than the postpartum period, with the exception of associations with symptoms of hyperactivity/inattention. Thus, the preschool age may be a period of development when children are especially sensitive to the consequences of their mother's mental health. ${ }^{9,12,13}$ Because small children rely on their mothers' emotional availability as they develop emotional and social competencies, maternal depression during this period may lead to disruption of normative early developmental and emotion regulating processes. ${ }^{55,56}$ We found no association between maternal depression occurring in pregnancy only and children's later behavior, reflecting inconsistent prior findings in this area. ${ }^{6,85758}$ This is not to say that maternal depression during fetal development does not affect children's development - either directly or indirectly (through birth weight, responsiveness or neurodevelopmental outcomes). ${ }^{4,6}$ However, in our study, this effect on children's behavior was only observable if the mother experienced depressive symptoms after the child's birth.

\section{Conclusion}

Maternal symptoms of depression are related to children's emotional and behavioral problems, particularly if they are persistent or occur when children are of preschool age. Future research should explore the impact of maternal depression on children's emotional and behavioral development at later ages relative to the influence of a mother's persistent depression. Families in which women experience chronic and severe depression represent a high risk group which requires special attention from healthcare professionals and prevention specialists. While routine screening for depression in pregnant women early in the postpartum period is common, these practices need to be extended through the child's early years to identify those whose mothers experience chronic depression, and introduce appropriate interventions or treatment as early as possible. Screening of 
maternal depression might occur at well-child visits, which seems feasible within the context of pediatric practices ${ }^{59,60}$. Our results further suggest maternal depression appears to have a negative impact on children's behavior even if maternal symptoms of depression are of intermediate level or occur after the post-partum period. When mothers report mild or moderate depressive symptoms and their offspring show emotional or behavioral problems, treatment should be targeted at both the child and his/her mother. Sensitizing pediatricians, primary care providers and mental health specialists to the importance of psychological distress even of moderate degree in mothers of young children, especially those of preschool age, may help reduce the burden of later emotional and behavioral difficulties in the next generation.

\section{List of abbreviations}

CES-D: Center for Epidemiological Studies Depression

EPDS: Edinburgh Postnatal Depression Scale

SDQ: Strengths and Difficulties Questionnaire

BIC: Bayesian information Criteria 


\section{References}

[1] Weissman MM, Wickramaratne P, Nomura Y, Warner V, Pilowsky D, Verdeli H. Offspring of depressed parents: 20 years later. Am J Psychiatry 2006; 163:1001-8.

[2] Goodman SH, Rouse MH, Connell AM, Broth MR, Hall CM, Heyward D. Maternal depression and child psychopathology: a meta-analytic review. Clin Child Fam Psychol Rev 2011; 14:1-27.

[3] Colman I, Ataullahjan A. Life course perspectives on the epidemiology of depression. Can J Psychiatry 2010; 55:622-32.

[4] Glover V. Annual research review: Prenatal stress and the origins of psychopathology: an evolutionary perspective. J Child Psychol Psychiatry 2011; 52:356-67.

[5] O'Connor TG, Monk C, Fitelson EM. Practitioner Review: Maternal mood in pregnancy and child development - implications for child psychology and psychiatry. J Child Psychol Psychiatry 2014; 55:99-111. [6] Field T. Prenatal depression effects on early development: A review. Infant Behav Dev 2011; 34:1-14.

[7] Kingston D, Tough S, Whitfield H. Prenatal and postpartum maternal psychological distress and infant development: a systematic review. Child Psychiatry Hum Dev 2012; 43:683-714.

[8] Bagner DM, Pettit JW, Lewinsohn PM, Seeley JR. Effect of maternal depression on child behavior: a sensitive period? J Am Acad Child Adolesc Psychiatry 2010; 49:699-707.

[9] Essex MJ, Klein MH, Miech R, Smider NA. Timing of initial exposure to maternal major depression and children's mental health symptoms in kindergarten. Br J Psychiatry 2001; 179:151-6.

[10] Kingston D, Tough S. Prenatal and postnatal maternal mental health and school-age child development: A systematic review. Matern Child Health J 2014; 18:1728-41.

[11] Mantymaa M, Puura K, Luoma I, Latva R, Salmelin RK, Tamminen T. Predicting internalizing and externalizing problems at five years by child and parental factors in infancy and toddlerhood. Child Psychiatry Hum Dev 2012; 43:153-70.

[12] Korhonen M, Luoma I, Salmelin R, Tamminen T. Maternal depressive symptoms: Associations with adolescents' internalizing and externalizing problems and social competence. Nord J Psychiatry 2014; 68:32332.

[13] Naicker K, Wickham M, Colman I. Timing of first exposure to maternal depression and adolescent emotional disorder in a national Canadian cohort. PloS one 2012; 7:e33422.

[14] Turney K. Pathways of disadvantage: explaining the relationship between maternal depression and children's problem behaviors. Soc Sci Res 2012; 41:1546-64.

[15] Brennan PA, Hammen C, Andersen MJ, Bor W, Najman JM, Williams GM. Chronicity, severity, and timing of maternal depressive symptoms: relationships with child outcomes at age 5. Dev Psychol 2000; 36:759-66.

[16] Fihrer I, McMahon CA, Taylor AJ. The impact of postnatal and concurrent maternal depression on child behaviour during the early school years. J Affect Disord 2009; 119:116-23.

[17] Nagin D. Group-based modeling of development. Cambridge, MA: Harvard University Press; 2005.

[18] Muthen B, Brown CH, Masyn K, Jo B, Khoo ST, Yang CC, et al. General growth mixture modeling for randomized preventive interventions. Biostatistics 2002; 3:459-75. 
[19] Campbell SB, Matestic P, von Stauffenberg C, Mohan R, Kirchner T. Trajectories of maternal depressive symptoms, maternal sensitivity, and children's functioning at school entry. Dev Psychol 2007; 43:1202-15.

[20] Campbell SB, Morgan-Lopez AA, Cox MJ, McLoyd VC. A latent class analysis of maternal depressive symptoms over 12 years and offspring adjustment in adolescence. J Abnormal Psychol 2009; 118:479-93.

[21] Gross HE, Shaw DS, Burwell RA, Nagin DS. Transactional processes in child disruptive behavior and maternal depression: A longitudinal study from early childhood to adolescence. Dev Psychopathol 2009; 21:139-56.

[22] Cents RAM, Diamantopoulou S, Hudziak JJ, Jaddoe VWV, Hofman A, Verhulst FC, et al. Trajectories of maternal depressive symptoms predict child problem behaviour: The Generation R Study. Psychol Med 2013; 43:13-25.

[23] Ashman SB, Dawson G, Panagiotides H. Trajectories of maternal depression over 7 years: relations with child psychophysiology and behavior and role of contextual risks. Dev Psychopathol 2008; 20:55-77.

[24] Essex MJ, Kraemer HC, Armstrong JM, Boyce WT, Goldsmith HH, Klein MH, et al. Exploring risk factors for the emergence of children's mental health problems. Arch Gen Psychiatry 2006; 63:1246-56.

[25] Drouillet P, Forhan A, De Lauzon-Guillain B, Thiebaugeorges O, Goua V, Magnin G, et al. Maternal fatty acid intake and fetal growth: evidence for an association in overweight women. The 'EDEN mother-child' cohort (study of pre- and early postnatal determinants of the child's development and health). Br J Nutr 2009; 101:583-91.

[26] Radloff LS. The CES-D Scale: A self-report depression scale for research in the general population. Applied Psychol Meas 1977; 1:385-401.

[27] Joiner TE, Walker RL, Pettit JW, Perez M, Cukrowicz KC. Evidence-based assessment of depression in adults. Psychol Assess 2005; 17:267-77.

[28] Marcus SM, Flynn HA, Blow FC, Barry KL. Depressive symptoms among pregnant women screened in obstetrics settings. J Womens Health 2003; 12:373-80.

[29] Canady RB, Stommel M, Holzman C. Measurement properties of the centers for epidemiological studies depression scale (CES-D) in a sample of African American and non-Hispanic White pregnant women. J Nurs Meas 2009; 17:91-104.

[30] Cox JL, Holden JM, Sagovsky R. Detection of postnatal depression. Development of the 10-item Edinburgh Postnatal Depression Scale. Br J Psychiatry 1987; 150:782-6.

[31] Norman GR, Streiner DL. Biostatistics: The Bare Essentials, 3e. Shelton: People's Medical Publishing HouseUSA; 2008.

[32] Goodman R. The Strengths and Difficulties Questionnaire: a research note. J Child Psychol Psychiatry 1997; 38:581-6.

[33] Goodman R, Scott S. Comparing the Strengths and Difficulties Questionnaire and the Child Behavior Checklist: is small beautiful? J Abnorm Child Psychol 1999; 27:17-24.

[34] Spielberger CD, Gorsuch RL, Lushene PR, Vagg PR, Jacobs AG. Manual for the State-Trait Anxiety Inventory (Form Y). Palo Alto: Consulting Psychologists Press, Inc.; 1983. 
[35] Nagin D. Analyzing developmental trajectories: A semiparametric, group-based approach. Psychol Meth 1999; 4:139-57.

[36] Jones BL, Nagin DS. Advances in group-based trajectory modeling and an SAS procedure for estimating them. Soc Meth Res 2007; 35:542-71.

[37] Guedeney N, Fermanian J. Validation study of the French version of the Edinburgh Postnatal Depression Scale (EPDS): new results about use and psychometric properties. Europ Psychiatry 1998; 13:83-9.

[38] Müller JM, Furniss T. Correction of distortions in distressed mothers' ratings of their preschool children's psychopathology. Psychiatry Res 2013; 210:294-301.

[39] Lewis KJS, Mars B, Lewis G, Rice F, Sellers R, Thapar AK, et al. Do parents know best? Parent-reported vs. child-reported depression symptoms as predictors of future child mood disorder in a high-risk sample. J Affect Disord 2012; 141:233-6.

[40] Dirks MA, De Los Reyes A, Briggs-Gowan M, Cella D, Wakschlag LS. Annual research review: embracing not erasing contextual variability in children's behavior - theory and utility in the selection and use of methods and informants in developmental psychopathology. J Child Psychol Psychiatry 2012; 53:558-74.

[41] Markon KE, Chmielewski M, Miller CJ. The reliability and validity of discrete and continuous measures of psychopathology: a quantitative review. Psycholl Bull 2011; 137:856-79.

[42] Heron J, O'Connor TG, Evans J, Golding J, Glover V. The course of anxiety and depression through pregnancy and the postpartum in a community sample. J Affect Disord 2004; 80:65-73.

[43] Wynter K, Rowe H, Fisher J. Common mental disorders in women and men in the first six months after the birth of their first infant: a community study in Victoria, Australia. J Affect Disord 2013; 151:980-5.

[44] Skouteris H, Wertheim EH, Rallis S, Milgrom J, Paxton SJ. Depression and anxiety through pregnancy and the early postpartum: an examination of prospective relationships. J Affect Disord 2009; 113:303-8.

[45] Farrell M, Howes S, Bebbington P, Brugha T, Jenkins R, Lewis G, et al. Nicotine, alcohol and drug dependence, and psychiatric comorbidity-results of a national household survey. Int Rev Psychiatry 2003; 15:50-6.

[46] Pinheiro RT, Magalhaes PV, Horta BL, Pinheiro KA, da Silva RA, Pinto RH. Is paternal postpartum depression associated with maternal postpartum depression? Population-based study in Brazil. Act Psychiatrica Scand 2006; 113:230-2.

[47] Connell AM, Goodman SH. The association between psychopathology in fathers versus mothers and children's internalizing and externalizing behavior problems: A meta-analysis. Psychol Bull 2002; 128:746-73.

[48] Korhonen M, Luoma I, Salmelin R, Tamminen T. A longitudinal study of maternal prenatal, postnatal and concurrent depressive symptoms and adolescent well-being. J Affect Disord 2012; 136:680-92.

[49] Oppenheimer CW, Hankin BL, Young JF, Smolen A. Youth genetic vulnerability to maternal depressive symptoms: 5-HTTLPR as moderator of intergenerational transmission effects in a multiwave prospective study. Depress Anxiety 2013; 30:190-6.

[50] Silberg JL, Maes H, Eaves LJ. Genetic and environmental influences on the transmission of parental depression to children's depression and conduct disturbance: an extended Children of Twins study. J Child Psychol Psychiatry 2010; 51:734-44. 
[51] Barker ED, Copeland W, Maughan B, Jaffee SR, Uher R. Relative impact of maternal depression and associated risk factors on offspring psychopathology. Br J Psychiatry 2012; 200:124-9.

[52] Gere MK, Hagen KA, Villabo MA, Arnberg K, Neumer SP, Torgersen S. Fathers' mental health as a protective factor in the relationship between maternal and child depressive symptoms. Depress Anxiety 2013; 30:31-8.

[53] Weaver CM, Shaw DS, Dishion TJ, Wilson MN. Parenting self-efficacy and problem behavior in children at high risk for early conduct problems: the mediating role of maternal depression. Infant Behav Dev 2008; 31:594-605.

[54] Wickramaratne P, Gameroff MJ, Pilowsky DJ, Hughes CW, Garber J, Malloy E, et al. Children of depressed mothers 1 year after remission of maternal depression: findings from the STAR*D-Child study. Am J Psychiatry 2011; 168:593-602.

[55] Silk JS, Shaw DS, Prout JT, O'Rourke F, Lane TJ, Kovacs M. Socialization of emotion and offspring internalizing symptoms in mothers with childhood-onset depression. J App Dev Psychol 2011; 32:127-36.

[56] Bocknek EL, Brophy-Herb HE, Fitzgerald H, Burns-Jager K, Carolan MT. Maternal psychological absence and toddlers' social-emotional development: interpretations from the perspective of boundary ambiguity theory. Fam Process 2012; 51:527-41.

[57] Van Batenburg-Eddes T, Brion MJ, Henrichs J, Jaddoe VW, Hofman A, Verhulst FC, et al. Parental depressive and anxiety symptoms during pregnancy and attention problems in children: a cross-cohort consistency study. J Child Psychol Psychiatry 2013; 54:591-600.

[58] Rice F, Harold GT, Boivin J, van den Bree M, Hay DF, Thapar A. The links between prenatal stress and offspring development and psychopathology: disentangling environmental and inherited influences. Psychol Med 2010; 40:335-45.

[59] Kemper KJ, Kelleher K, Olson AL. Implementing maternal depression screening. Pediatrics 2007; 120:448-9. [60] Wu YP, Selig JP, Roberts MC, Steele RG. Trajectories of postpartum maternal depressive symptoms and children's social skills. J Child Fam Stud 2011; 20:414-23. 


\begin{tabular}{|c|c|c|}
\hline & No. (\%) & mean (SD) \\
\hline \multicolumn{3}{|l|}{ Maternal characteristics } \\
\hline Age at birth (years) & & $30.13(4.70)$ \\
\hline Educational level (years) & & $14.01(2.59)$ \\
\hline Maternal anxiety (STAI) in pregnancy & & $10.05(9.66)$ \\
\hline \multicolumn{3}{|c|}{ Maternal history of mental health problems } \\
\hline No & $1012(85.5)$ & \\
\hline Yes & $171(14.5)$ & \\
\hline \multicolumn{3}{|l|}{ Maternal antidepressant use } \\
\hline No & $1070(90.4)$ & \\
\hline Yes & $113(9.6)$ & \\
\hline \multicolumn{3}{|l|}{ Prenatal substance use } \\
\hline No & $804(68.0)$ & \\
\hline Yes & $379(32.0)$ & \\
\hline Breastfeeding (duration in months) & & $3.46(4.20)$ \\
\hline \multicolumn{3}{|l|}{ Maternal depressive symptoms } \\
\hline In pregnancy & & $11.04(7.76)$ \\
\hline 4 months after child's birth & & $4.91(4.72)$ \\
\hline 8 months after child's birth & & $4.73(4.61)$ \\
\hline 12 months after child's birth & & $4.33(4.51)$ \\
\hline 3 years after child's birth & & $9.53(7.95)$ \\
\hline 5 years after child's birth & & $9.31(8.05)$ \\
\hline \multicolumn{3}{|l|}{ Family characteristics } \\
\hline \multicolumn{3}{|l|}{ Family income } \\
\hline$<1500$ euros/ month & $352(30.3)$ & \\
\hline$\geq 1500$ euros/ month & $811(69.7)$ & \\
\hline \multicolumn{3}{|l|}{ Family situation } \\
\hline Parents living together & $1007(85.8)$ & \\
\hline Parents separated & $166(14.2)$ & \\
\hline Child's number of siblings & & $0.83(0.88)$ \\
\hline \multicolumn{3}{|l|}{ Child care arrangements } \\
\hline Mother & $196(18.5)$ & \\
\hline Others & $866(81.5)$ & \\
\hline \multicolumn{3}{|l|}{ Partner alcohol problems } \\
\hline No & $1116(96.1)$ & \\
\hline
\end{tabular}




\begin{tabular}{|c|c|c|}
\hline Yes & $45(3.9)$ & \\
\hline \multicolumn{3}{|l|}{ Mother's experience of domestic violence } \\
\hline No & $1093(94.1)$ & \\
\hline Yes & $68(5.9)$ & \\
\hline \multicolumn{3}{|l|}{ Mother's social support } \\
\hline No & $35(3.0)$ & \\
\hline Yes & $1138(97.0)$ & \\
\hline \multicolumn{3}{|l|}{ Child characteristics } \\
\hline \multicolumn{3}{|l|}{ Sex } \\
\hline Male & $626(52.9)$ & \\
\hline Female & $557(47.1)$ & \\
\hline \multicolumn{3}{|l|}{ Preterm birth (<37weeks) } \\
\hline No & $1115(94.3)$ & \\
\hline Yes & $68(5.7)$ & \\
\hline \multicolumn{3}{|l|}{ Small for gestational age } \\
\hline No & $1069(90.4)$ & \\
\hline Yes & $114(9.6)$ & \\
\hline \multicolumn{3}{|c|}{$\begin{array}{l}\text { Children's behavioral scores at age } 5 \text { (cut-point for scores at clinical } \\
\text { level) }\end{array}$} \\
\hline Emotional symptoms ( $\geq 4)$ & & $2.13(1.88)$ \\
\hline Conduct problems ( $\geq 5)$ & & $2.36(2.04)$ \\
\hline Peer relationship symptoms $(\geq 2)$ & & $1.20(1.32)$ \\
\hline Pro-social behavior $(\leq 6)$ & & $8.37(1.68)$ \\
\hline Hyperactivity/inattention ( $\geq 6$ ) & & $3.07(2.39)$ \\
\hline Overall behavioral score ( $\geq 14)$ & & $8.75(5.21)$ \\
\hline
\end{tabular}


Table 2 Trajectory of maternal symptoms of depression and children's behavioral scores at age 5 in the EDEN cohort study- linear regression models

( $n=1,095,2003-2011$ France, $6,95 \% \mathrm{Cl}$, $p$-value)

\begin{tabular}{|c|c|c|c|c|c|c|c|c|c|c|c|c|}
\hline & \multicolumn{12}{|c|}{ Children's behavioral scores } \\
\hline & \multicolumn{2}{|c|}{ Emotional symptoms } & \multicolumn{2}{|c|}{ Conduct problems } & \multicolumn{2}{|c|}{$\begin{array}{l}\text { Peer relationship } \\
\text { problems }\end{array}$} & \multicolumn{2}{|c|}{ Prosocial behavior } & \multicolumn{2}{|c|}{$\begin{array}{c}\text { Symptoms of } \\
\text { hyperactivity/ } \\
\text { inattention }\end{array}$} & \multicolumn{2}{|c|}{ Overall behavioral score } \\
\hline & $B(95 \% \mathrm{Cl})$ & $p$ & $B(95 \% C l)$ & $p$ & $B(95 \% C l)$ & $p$ & $B(95 \% \mathrm{Cl})$ & $p$ & $B(95 \% C l)$ & $p$ & $B(95 \% \mathrm{Cl})$ & $p$ \\
\hline $\begin{array}{l}\text { Trajectory of } \\
\text { maternal } \\
\text { symptoms of } \\
\text { depression }\end{array}$ & & & & & & & & & & & & \\
\hline \multicolumn{13}{|l|}{ Unadjusted model } \\
\hline No symptoms & $0.00 \quad$ (ref) & & $0.00 \quad$ (ref) & & $0.00 \quad$ (ref) & & $0.00 \quad$ (ref) & & $0.00 \quad$ (ref) & & $0.00 \quad$ (ref) & \\
\hline $\begin{array}{l}\text { Persistent } \\
\text { intermediate-level } \\
\text { symptoms }\end{array}$ & $.69(.45-.94)$ & $\begin{array}{l}.000 \\
* * *\end{array}$ & $.67(.40-.94)$ & $\begin{array}{l}.000 \\
* * *\end{array}$ & $.35(.17-.52)$ & $\begin{array}{l}.000 \\
* * *\end{array}$ & $-.35(-.57--.12)$ & $\begin{array}{c}.002 \\
* *\end{array}$ & $.79(.48-1.11)$ & $\begin{array}{l}.000 \\
* * *\end{array}$ & $2.51(1.84-3.18)$ & $\begin{array}{l}.000 \\
* * *\end{array}$ \\
\hline $\begin{array}{l}\text { Persistent high- } \\
\text { level symptoms }\end{array}$ & $1.30(.79-1.81)$ & $\begin{array}{l}.000 \\
* * *\end{array}$ & $1.82(1.20-2.32)$ & $\begin{array}{l}.000 \\
* * *\end{array}$ & $.99(.64-1.36)$ & $\begin{array}{l}.000 \\
* * *\end{array}$ & $-.99(-1.44--.52)$ & $\begin{array}{l}.000 \\
* * *\end{array}$ & $1.40(.75-2.05)$ & $\begin{array}{l}.000 \\
* * *\end{array}$ & $5.52(4.14-6.90)$ & $\begin{array}{l}.000 \\
* * *\end{array}$ \\
\hline $\begin{array}{l}\text { High symptoms in } \\
\text { pregnancy only }\end{array}$ & $.15(-.42-.73)$ & .60 & $.10(-.51-.72)$ & .76 & $.26(-.14-.67)$ & .20 & $-.25(-.77-.27)$ & .34 & $.55(-.19-1.28)$ & .15 & $1.06(-.49-2.62)$ & .18 \\
\hline \multicolumn{13}{|l|}{ Adjusted model $^{\mathrm{a}}$} \\
\hline No symptoms & $0.00 \quad$ (ref) & & $0.00 \quad$ (ref) & & $0.00 \quad$ (ref) & & $0.00 \quad$ (ref) & & $0.00 \quad$ (ref) & & $0.00 \quad$ (ref) & \\
\hline $\begin{array}{l}\text { Persistent } \\
\text { intermediate-level } \\
\text { symptoms }\end{array}$ & $.62(.33-.91)$ & $\begin{array}{l}.000 \\
* * *\end{array}$ & $.49(.18-.80)$ & $\begin{array}{c}.002 \\
* *\end{array}$ & $.34(.13-.54)$ & $\begin{array}{l}.001 \\
* * *\end{array}$ & $-.27(-.53--.06)$ & $\begin{array}{l}.04 \\
*\end{array}$ & $.66(.30-1.01)$ & $\begin{array}{l}.000 \\
* * *\end{array}$ & $2.10(1.33-2.88)$ & $\begin{array}{l}.000 \\
* * *\end{array}$ \\
\hline $\begin{array}{l}\text { Persistent high- } \\
\text { level symptoms }\end{array}$ & $1.29(.64-1.90)$ & $\begin{array}{l}.000 \\
* * * \\
\end{array}$ & $1.80(1.13-2.48)$ & $\begin{array}{l}.000 \\
* * * \\
\end{array}$ & $.95(.51-1.39)$ & $\begin{array}{l}.000 \\
* * *\end{array}$ & $-.99(-1.56--.43)$ & $\begin{array}{l}.001 \\
* * * \\
\end{array}$ & $1.58(.81-2.34)$ & $\begin{array}{l}.000 \\
* * *\end{array}$ & $5.60(3.92-7.27)$ & $\begin{array}{l}.000 \\
* * * \\
\end{array}$ \\
\hline $\begin{array}{l}\text { High symptoms in } \\
\text { pregnancy only }\end{array}$ & $.13(-.59-.85)$ & .72 & $.03(-.75-.79)$ & .94 & $.32(-.19-.83)$ & .22 & $.02(-.63-.67)$ & .95 & $.19(-.68-1.06)$ & .67 & $.66(-1.25-2.58)$ & .49 \\
\hline $\begin{array}{l}\text { High symptoms in } \\
\text { preschool period } \\
\text { only }\end{array}$ & $.84(.25-1.42)$ & $\begin{array}{l}.005 \\
* *\end{array}$ & $.52(-.11-1.14)$ & .11 & $.60(.19-1.01)$ & $\begin{array}{c}.004 \\
* *\end{array}$ & $-.30(-.82-.23)$ & .26 & $.29(-.42-1.00)$ & .42 & $2.25(.69-3.79)$ & $\begin{array}{c}.004 \\
* *\end{array}$ \\
\hline
\end{tabular}




\begin{tabular}{|c|c|c|c|c|c|c|c|c|c|c|c|c|}
\hline \multicolumn{13}{|l|}{ Adjusted model $^{b}$} \\
\hline No symptoms & $0.00 \quad$ (ref) & & $0.00 \quad$ (ref) & & $0.00 \quad$ (ref) & & $0.00 \quad$ (ref) & & $0.00 \quad$ (ref) & & $0.00 \quad$ (ref) & \\
\hline $\begin{array}{l}\text { Persistent } \\
\text { intermediate-level } \\
\text { symptoms }\end{array}$ & $.54(.19-.89)$ & $\begin{array}{c}.003 \\
* *\end{array}$ & $.39(.01-.76)$ & $\begin{array}{l}.04 \\
*\end{array}$ & $.22(-.03-.47)$ & .07 & $-.18(-.49-.13)$ & .25 & $.54(.11-.97)$ & $\begin{array}{l}.01 \\
* *\end{array}$ & $1.69(.76-2.63)$ & $\begin{array}{l}.000 \\
* * *\end{array}$ \\
\hline $\begin{array}{l}\text { Persistent high- } \\
\text { level symptoms }\end{array}$ & $1.36(.68-2.04)$ & $\begin{array}{l}.000 \\
* * *\end{array}$ & $1.61(.88-2.34)$ & $\begin{array}{l}.000 \\
* * *\end{array}$ & $\begin{array}{c}1.21(.73- \\
1.68)\end{array}$ & $\begin{array}{l}.000 \\
* * *\end{array}$ & $-.91(-1.52--.30)$ & $\begin{array}{c}.003 \\
* *\end{array}$ & $1.37(.54-2.20)$ & $\begin{array}{l}.001 \\
* * *\end{array}$ & $5.55(3.73-7.36)$ & $\begin{array}{l}.000 \\
* * *\end{array}$ \\
\hline $\begin{array}{l}\text { High symptoms in } \\
\text { pregnancy only }\end{array}$ & $.37(-.59-.13)$ & .45 & $.39(-.64-1.42)$ & .45 & $.19(-.48-.86)$ & .57 & $.28(-.58-1.14)$ & .53 & $.47(-.69-1.64)$ & .43 & $1.42(-1.13-3.97)$ & .27 \\
\hline $\begin{array}{l}\text { High symptoms in } \\
\text { preschool period } \\
\text { only }\end{array}$ & $.94(.35-1.53)$ & $\begin{array}{c}.002 \\
* *\end{array}$ & $.52(-.12-1.15)$ & .11 & $.67(.25-1.08)$ & $\begin{array}{c}.002 \\
* *\end{array}$ & $-.57(-1.10-.03)$ & $\begin{array}{c}.04 \\
*\end{array}$ & $.78(.05-1.49)$ & $\begin{array}{c}.03 \\
*\end{array}$ & $2.89(1.32-4.48)$ & $\begin{array}{l}.000 \\
* * *\end{array}$ \\
\hline \multicolumn{13}{|c|}{ 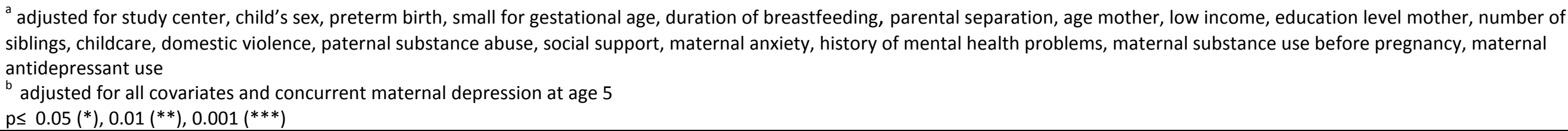 } \\
\hline
\end{tabular}




\begin{tabular}{|c|c|c|c|c|c|c|c|c|c|c|c|c|}
\hline & \multicolumn{2}{|c|}{ Emotional symptoms } & \multicolumn{2}{|c|}{ Conduct problems } & \multicolumn{2}{|c|}{$\begin{array}{l}\text { Peer relationship } \\
\text { problems }\end{array}$} & \multicolumn{2}{|c|}{ Prosocial behavior } & \multicolumn{2}{|c|}{$\begin{array}{c}\text { Symptoms of } \\
\text { hyperactivity/ } \\
\text { inattention }\end{array}$} & \multicolumn{2}{|c|}{ Overall problem behavior } \\
\hline & $B(95 \% \mathrm{Cl})$ & $p$ & $B(95 \% \mathrm{Cl})$ & $p$ & $B(95 \% \mathrm{Cl})$ & $p$ & B (95\% Cl) & $p$ & B (95\% Cl) & $p$ & $B(95 \% \mathrm{Cl})$ & $p$ \\
\hline \multicolumn{13}{|l|}{ Model 1} \\
\hline Intercept & $1.94(.00-3.88)$ & .05 & $1.86(-.20-3.93)$ & .08 & $2.60(1.25-3.96)$ & .000 & $7.08(5.34-8.82)$ & .000 & $5.29(2.94-7.64)$ & .000 & $11.70(6.57-16.84)$ & .000 \\
\hline $\begin{array}{l}\text { Depression in } \\
\text { pregnancy }\end{array}$ & $.10(-.24-.44)$ & .57 & $.33(-.03-.70)$ & .07 & $-.02(-.26-.22)$ & .87 & $-.07(-.38-.24)$ & .65 & $-.26(-.66-.16)$ & .22 & $.16(-.75-1.06)$ & .74 \\
\hline Intercept & $1.94(.00-3.88)$ & .05 & $1.86(-.20-3.93)$ & .08 & $2.60(1.25-3.96)$ & .000 & $7.08(5.34-8.82)$ & .000 & $5.29(2.94-7.64)$ & .000 & $11.70(6.57-16.84)$ & .000 \\
\hline $\begin{array}{l}\text { Depression in } \\
\text { postpartum period }\end{array}$ & $.31(.00-.61)$ & $\begin{array}{c}.04 \\
* \\
\end{array}$ & $.39(.06-.71)$ & $\begin{array}{c}.02 \\
* \\
\end{array}$ & $.31(.10-.52)$ & $\begin{array}{c}.005 \\
* *\end{array}$ & $-.08(-.36-.19)$ & .56 & $.41(.04-.78)$ & $\begin{array}{c}.03 \\
* \\
\end{array}$ & $1.41(.61-2.22)$ & $\begin{array}{l}.001 \\
* * * \\
\end{array}$ \\
\hline Intercept & $1.94(.00-3.88)$ & .05 & $1.86(-.20-3.93)$ & .08 & $2.60(1.25-3.96)$ & .000 & $7.08(5.34-8.82)$ & .000 & $5.29(2.94-7.64)$ & .000 & $11.70(6.57-16.84)$ & .000 \\
\hline $\begin{array}{l}\text { Depression in } \\
\text { preschool period }\end{array}$ & $.55(.26-.85)$ & $\begin{array}{l}.000 \\
* * * \\
\end{array}$ & $.56(.25-.87)$ & $\begin{array}{l}.001 \\
* * * \\
\end{array}$ & $.44(.23-.64)$ & $\begin{array}{l}.000 \\
* * *\end{array}$ & $-.28(-.54--.01)$ & $\begin{array}{c}.04 \\
* \\
\end{array}$ & $.70(.34-1.06)$ & $\begin{array}{l}.000 \\
* * * \\
\end{array}$ & 2. 25 (1.47-3.03) & $\begin{array}{l}.000 \\
* * * \\
\end{array}$ \\
\hline \multicolumn{13}{|l|}{ Model 2} \\
\hline Intercept & $2.60(.45-4.76)$ & .02 & $3.01(.76-5.28)$ & .009 & $2.97(1.47-4.47)$ & .000 & $6.78(4.88-8.68)$ & .000 & $6.54(3.94-9.15)$ & .000 & $15.14(9.46-20.81)$ & .000 \\
\hline $\begin{array}{l}\text { Depression in } \\
\text { pregnancy }\end{array}$ & $.19(-.16-.55)$ & .29 & $.39(.02-.77)$ & $\begin{array}{c}.04 \\
* \\
\end{array}$ & $.04(-.21-.29)$ & .74 & $-.06(-.38-.26)$ & .72 & $-.24(-.67-.20)$ & .29 & $.39(-.55-1.34)$ & .42 \\
\hline Intercept & $2.60(.45-4.76)$ & .02 & $3.01(.76-5.28)$ & .009 & $2.97(1.47-4.47)$ & .000 & $6.78(4.88-8.68)$ & .000 & $6.54(3.94-9.15)$ & .000 & $15.14(9.46-20.81)$ & .000 \\
\hline $\begin{array}{l}\text { Depression in } \\
\text { postpartum period }\end{array}$ & $.31(-.01-.63)$ & .05 & $.46(.13-.80)$ & $\begin{array}{c}.007 \\
* *\end{array}$ & $.28(.06-.50)$ & $\begin{array}{c}.02 \\
* \\
\end{array}$ & $-.08(-.37-.19)$ & .56 & $.51(.12-.89)$ & $\begin{array}{l}.01 \\
* * \\
\end{array}$ & $1.57(.72-2.41)$ & $\begin{array}{l}.000 \\
* * * \\
\end{array}$ \\
\hline Intercept & $2.60(.45-4.76)$ & .02 & $3.01(.76-5.28)$ & .009 & $2.97(1.47-4.47)$ & .000 & $6.78(4.88-8.68)$ & .000 & $6.54(3.94-9.15)$ & .000 & $15.14(9.46-20.81)$ & .000 \\
\hline $\begin{array}{l}\text { Depression in } \\
\text { preschool period }\end{array}$ & $.45(.11-.80)$ & $\begin{array}{l}.01 \\
* *\end{array}$ & $.49(.14-.86)$ & $\begin{array}{c}.007 \\
* * \\
\end{array}$ & $.52(.29-.76)$ & $\begin{array}{l}.000 \\
* * * \\
\end{array}$ & $-.39(-.69--.09)$ & $\begin{array}{l}.01 \\
* * \\
\end{array}$ & $.44(.03-.85)$ & $\begin{array}{c}.03 \\
* \\
\end{array}$ & $1.91(1.01-2.82)$ & $\begin{array}{l}.000 \\
* * * \\
\end{array}$ \\
\hline \multicolumn{13}{|c|}{$\begin{array}{l}\text { Model 1: adjusted for study center, child's sex, preterm birth, small for gestationa } \\
\text { number of siblings, childcare, domestic violence, paternal substance abuse, social } \\
\text { maternal antidepressant use, depression status } \\
\text { Model } 2 \text { : adjusted for all covariates and concurrent maternal depression at age } 5 \\
p \leq 0.05(*), 0.01(* *), 0.001(* * *)\end{array}$} \\
\hline
\end{tabular}


Figure 1 Trajectories of maternal symptoms of depression by child's age in months in the EDEN cohort study ( $n=1183,2003-2011$, France).

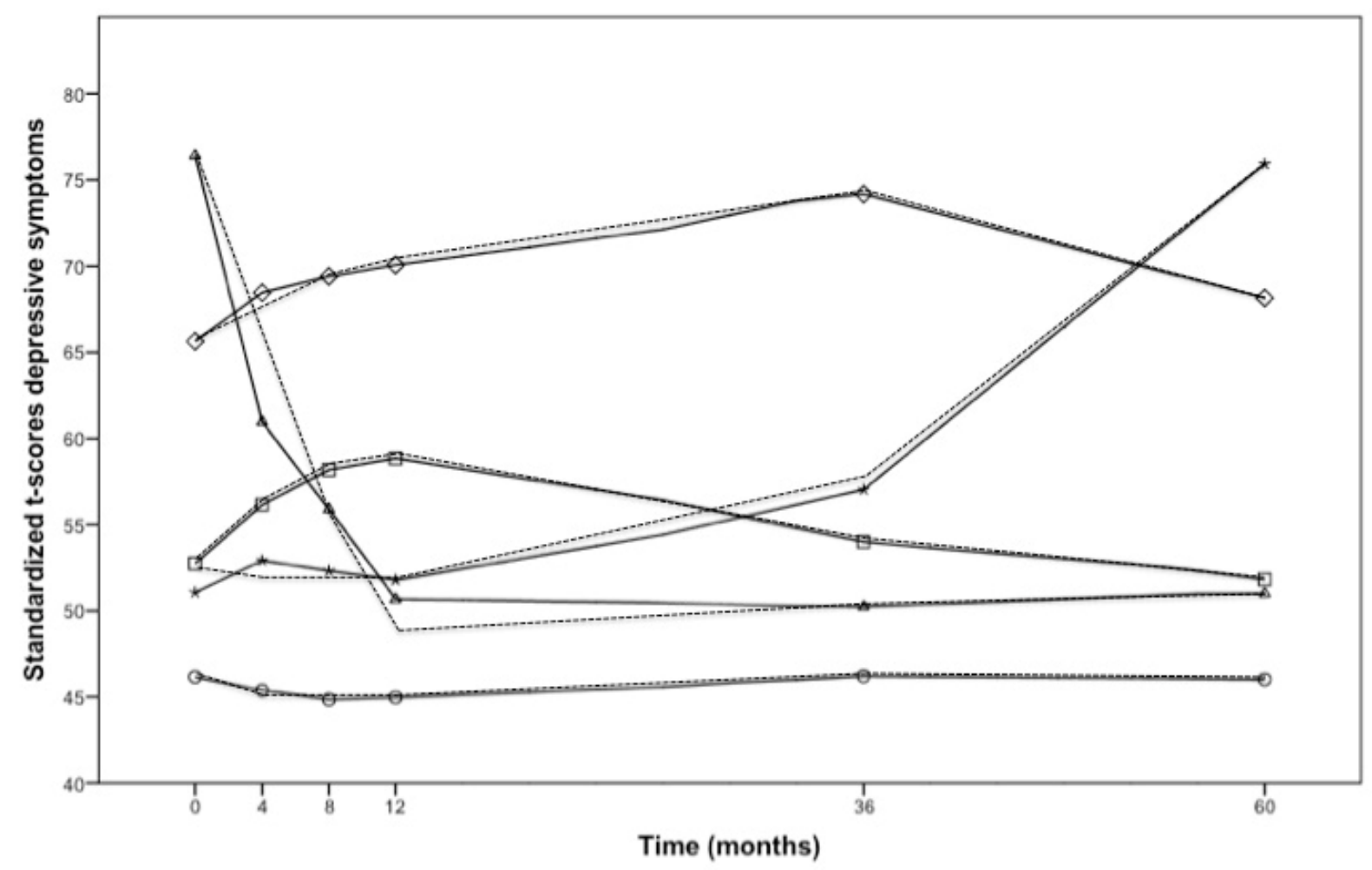

